\title{
Transcriptome profiling of posterior kidney of brown trout, Salmo trutta, during proliferative kidney disease
}

\author{
Arun Sudhagar ${ }^{1,3}$, Reinhard Ertl ${ }^{2}$, Gokhlesh Kumar ${ }^{1 *}$ (D) and Mansour El-Matbouli ${ }^{1}$
}

\begin{abstract}
Background: Tetracapsuloides bryosalmonae is a myxozoan parasite which causes economically important and emerging proliferative kidney disease (PKD) in salmonids. Brown trout, Salmo trutta is a native fish species of Europe, which acts as asymptomatic carriers for T. bryosalmonae. There is only limited information on the molecular mechanism involved in the kidney of brown trout during T. bryosalmonae development. We employed RNA sequencing (RNA-seq) to investigate the global transcriptome changes in the posterior kidney of brown trout during T. bryosalmonae development.

Methods: Brown trout were exposed to the spores of T. bryosalmonae and posterior kidneys were collected from both exposed and unexposed control fish. cDNA libraries were prepared from the posterior kidney and sequenced. Bioinformatics analysis was performed using standard pipeline of quality control, reference mapping, differential expression analysis, gene ontology, and pathway analysis. Quantitative real time PCR was performed to validate the transcriptional regulation of differentially expressed genes, and their correlation with RNA-seq data was statistically analyzed.
\end{abstract}

Results: Transcriptome analysis identified 1169 differentially expressed genes in the posterior kidney of brown trout, out of which 864 genes (74\%) were upregulated and 305 genes (26\%) were downregulated. The upregulated genes were associated with the regulation of immune system process, vesicle-mediated transport, leucocyte activation, and transport, whereas the downregulated genes were associated with endopeptidase regulatory activity, phosphatidylcholine biosynthetic process, connective tissue development, and collagen catabolic process.

Conclusion: To our knowledge, this is the first RNA-seq based transcriptome study performed in the posterior kidney of brown trout during active T. bryosalmonae development. Most of the upregulated genes were associated with the immune system process, whereas the downregulated genes were associated with other metabolic functions. The findings of this study provide insights on the immune responses mounted by the brown trout on the developing parasite, and the host molecular machineries modulated by the parasite for its successful multiplication and release.

Keywords: Myxozoan, Tetracapsuloides bryosalmonae, Salmonids, RNA-seq, Gene expression

\section{Background}

Proliferative kidney disease (PKD) is an emerging disease among salmonids caused by the extracellular myxozoan parasite Tetracapsuloides bryosalmonae. PKD is widely prevalent in Europe and North America [1]. PKD is of

\footnotetext{
*Correspondence: gokhlesh.kumar@vetmeduni.ac.at

${ }^{1}$ Clinical Division of Fish Medicine, University of Veterinary Medicine,

Vienna, Austria

Full list of author information is available at the end of the article
}

substantial importance, as it causes significant economic losses and ecological impacts in farmed and wild salmonids, respectively. Moreover, climate change driven rising water temperature can accelerate the T. bryosalmonae multiplication in fish which elevates the disease severity and associated mortalities, and also favours propagation of the parasite [2-4]. Scientific evidence points towards T. bryosalmonae as one of the major reasons for the protracted decline of endemic salmonids including brown 
trout (Salmo trutta) in the Alpine streams of Europe [5, 6]. In 2016 massive mortality of fishes, particularly mountain whitefish (Prosopium williamsoni) occurred due to T. bryosalmonae outbreak at the Yellowstone River, Montana, USA and a large section of the river was refrained from access to the public [7].

The life-cycle of T. bryosalmonae involves two hosts, an invertebrate bryozoan and a vertebrate salmonid fish $[8,9]$. Infected bryozoans release parasite spores into the water, which enters the fish via gills. The entered parasite migrates via bloodstream to the kidney and undergoes extra-sporogonic proliferation and differentiation through sporogenesis $[10,11]$. The sporogenesis of the parasite in the interstitial tissue of kidney results in the proliferation of leucocytes and granulomatous cellular response, which leads to the swelling of kidney [12-14]. The mature parasitic spores are released by infected fish, mainly brown trout and brook trout, via urine into the aquatic environment, and readily infect bryozoans [9].

Apart from excretory function, teleost kidney serves as complex multifunctional immune organ. Teleosts lack bone marrow and the kidney is analogous to mammalian bone marrow for immune function [15]. Anterior kidney of teleosts performs haematopoiesis, production and maturation of B lymphocytes. The matured B lymphocytes then migrate to either spleen or posterior kidney for activation [16]. Interestingly, T. bryosalmonae can develop and multiply in the kidney of salmonids, which is an active site of immune response.

Previous studies have demonstrated that the European strain of $T$. bryosalmonae has co-evolved with the endemic brown trout host in which the parasite can complete the life-cycle, whereas the rainbow trout (Oncorhynchus mykiss) cannot release the mature spores and remains as a dead end fish host [17]. In addition, the parasite can establish long-term persistence in brown trout and shed contagious spores even after five years post-infection [18]. Rainbow trout has been extensively studied in response to PKD and the disease pathogenesis is defined by a profound dysregulation of B cell subsets and cytokines of T-helper cells, decrease of myeloid cells and increase of lymphocytes, and overexpression of suppressors of cytokine signaling (SOCS) genes [4, 19-25]. However, only few gene expression studies have been investigated in the kidney of PKD-affected brown trout $[24,26]$. Although these studies are important, global transcriptome analysis of the posterior kidney of brown trout during PKD is still needed to visualize a broader picture during host-parasite interaction. Furthermore, there are still many open questions about the molecular factors of brown trout, influenced for successful proliferation, chronic subclinical persistence and release of T. bryosalmonae. RNA sequencing (RNA-seq)-based transcriptome analysis can provide insights and serve as a valuable tool to understand the host-parasite interaction [27].

Here, we employed transcriptome analysis in search of meaningful biological insights of transcripts during T. bryosalmonae proliferation in the posterior kidney of brown trout. Furthermore, we displayed the global kidney transcriptome responses by defining the most relevant gene ontology terms and pathways involved in PKD pathogenesis.

\section{Methods}

\section{Brown trout maintenance}

Specific pathogen-free (SPF) brown trout (mean length $12 \pm 2 \mathrm{~cm}$ ) were procured from a certified Austrian hatchery and acclimatized for 4 weeks. Fish $(n=10)$ were tested randomly for the presence of bacterial, viral and parasitic infection including T. bryosalmonae by our routine diagnostic procedures including PCR. All the tested fish were observed to be disease-free. Prior to the experiment, fish were acclimatized in 1000-l tanks with continuous flow through freshwater system with water temperature $15 \pm 1{ }^{\circ} \mathrm{C}$ and fed ad libitum with commercial trout feed.

\section{Brown trout experiment}

SPF brown trout $(n=69)$ were divided equally to three tanks (23 fish per tank). Fish from each tank were exposed to parasite spores released from the parasite sacs $(n=150)$, according to Kumar et al. [28]. At the same time, 69 SPF brown trout were maintained separately as unexposed control. The fish were maintained in 100-1 aquarium with continuous flow through freshwater system at $15 \pm 1{ }^{\circ} \mathrm{C}$ with sufficient feeding. Moribund fish were immediately removed from the parasite-exposed tanks and were euthanized. For each sampling, the fish $(n=9)$ from unexposed and exposed groups were euthanized using buffered MS-222 anesthetic (Sigma-Aldrich, Steinheim, Germany). Blood and different organs including posterior kidney were sampled at 2, 4, 6, 8, 10, 12 and 17 weeks post-exposure (wpe). The organs of each fish were divided into two portions, one fixed in $10 \%$ neutralbuffered formalin for histological investigation, and the second portion fixed in RNAlater (Sigma-Aldrich) or used to purify parasites for molecular studies.

\section{RNA extraction, library preparation and sequencing}

The optimal time point for the RNA-seq was determined by the presence of numerous interstitial proliferating $T$. bryosalmonae in the posterior kidney detected using histology and immunohistochemistry [28]. The parasiteexposed brown trout kidney samples collected at 12 wpe had pronounced necrotic changes, degenerated renal 
tubules and reduction of melanomacrophages along with numerous interstitial pre-sporogenic stages of $T$. bryosalmonae (Fig. 1a, b). No parasite or renal changes were observed in the unexposed control kidney samples (Fig. 1c).

Twelve cDNA libraries (for 6 exposed and 6 unexposed control fish) were generated and sequenced. Briefly, total RNA was extracted from the posterior kidney samples of exposed $(n=6)$ and unexposed control $(n=6)$ brown trout using RNeasy Mini Kit (Qiagen, Hilden, Germany) with an on-column DNase digestion step. The purity and integrity of the extracted RNA were accessed with a 4200 TapeStation (Agilent, Santa Clara, CA, USA) using the RNA ScreenTape assay. All the samples had RIN values above 7.0 and were used for cDNA library preparation. Briefly, $500 \mathrm{ng}$ total RNA per sample were used for library preparation with the TruSeq RNA Library Prep Kit v2 (Illumina, San Diego, CA, USA) according to the manufacturer's protocol. Library quality control was done with the D1000 ScreenTape assay (Agilent, Santa Clara, CA, USA) on the 4200 TapeStation. All the 12 cDNA libraries were sequenced (100-bp single reads) on two lanes of an Illumina HiSeq 2500 platform.

\section{Mapping and differential gene expression analysis}

The sequence data were analyzed using CLC Genomics Workbench 12 (Qiagen, Aarhus, Denmark). The raw sequence reads were subjected to quality (limit $=0.05$ and maximum 2 ambiguous nucleotides allowed) and adapter trimming. Reads shorter than 25 nucleotides were discarded. Currently, no genome data are available for brown trout and hence, de novo assembled brown trout transcriptome (GenBank: GFIS00000000) taken from the NCBI TSA database were used as a reference [29]. The trimmed reads were mapped against the transcriptome reference using the default mapping parameters of the CLC Genomics RNA-seq tool. Additionally, for comparison, mapping was done using the genomes of the closely related rainbow trout (GenBank: GCA_002163495.1) and Atlantic salmon (Salmo salar) (GenBank: GCA_000233375.4) as reference. However, the mapping percentage was higher with brown trout transcriptome (90\%) compared to rainbow trout genome (76\%) and Atlantic salmon genome (84\%) (Table 1). Therefore, brown trout transcriptome was considered a better reference and further used for differential expression analysis of posterior kidney. Read counts of

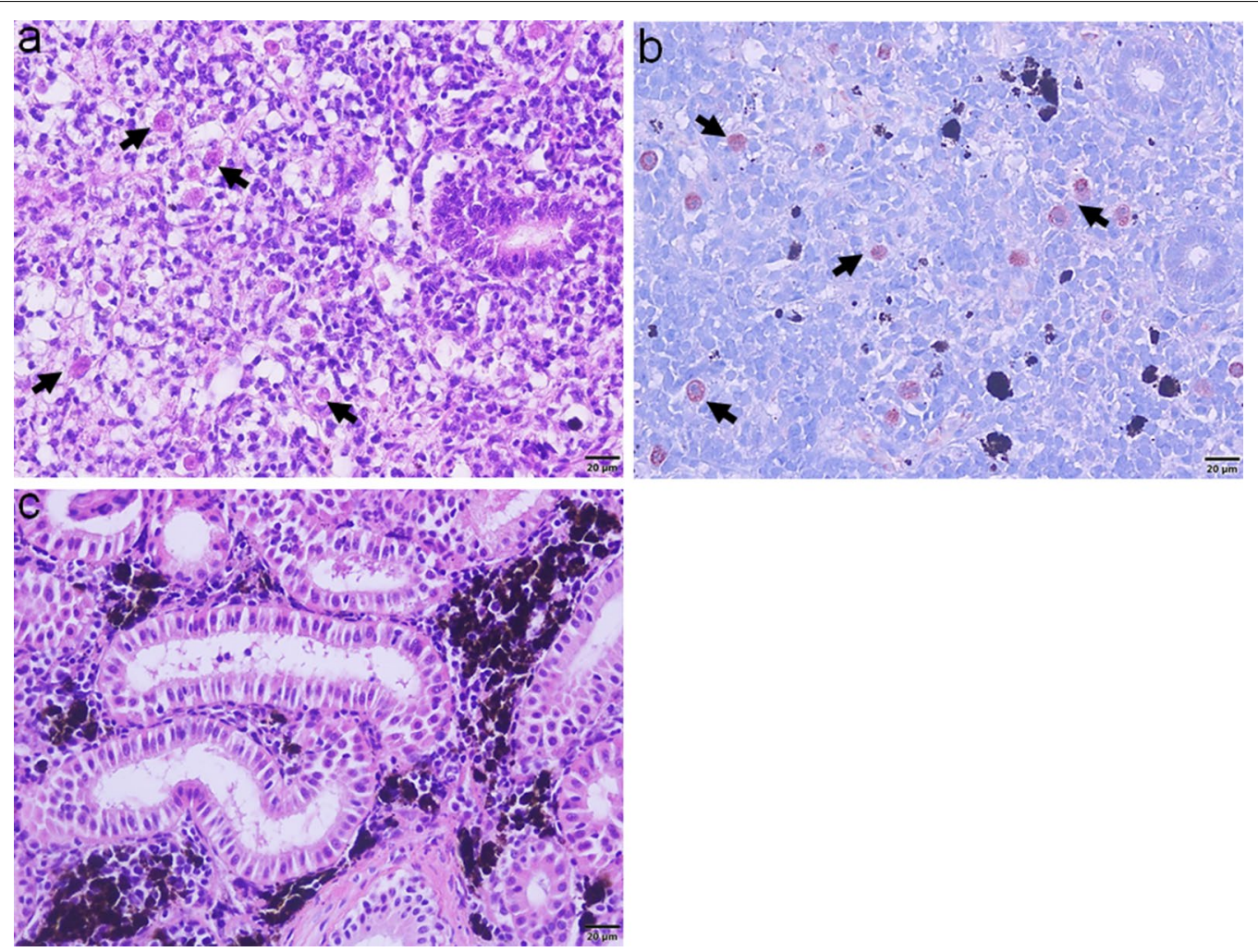

Fig. 1 Histological sections of brown trout posterior kidney. a Tetracapsuloides bryosalmonae-exposed posterior kidney section shows T. bryosalmonae (arrows) proliferation, pronounced tubular degeneration and reduction of melanomacrophages at 12 weeks post-exposure (H\&E staining). b Immunohistostaining shows interstitial extrasporogonic stages of T. bryosalmonae (arrows) in the posterior kidney. c No parasite or any renal changes were observed in the unexposed posterior control kidney (H\&E staining). Scale-bars: $20 \mu \mathrm{m}$ 


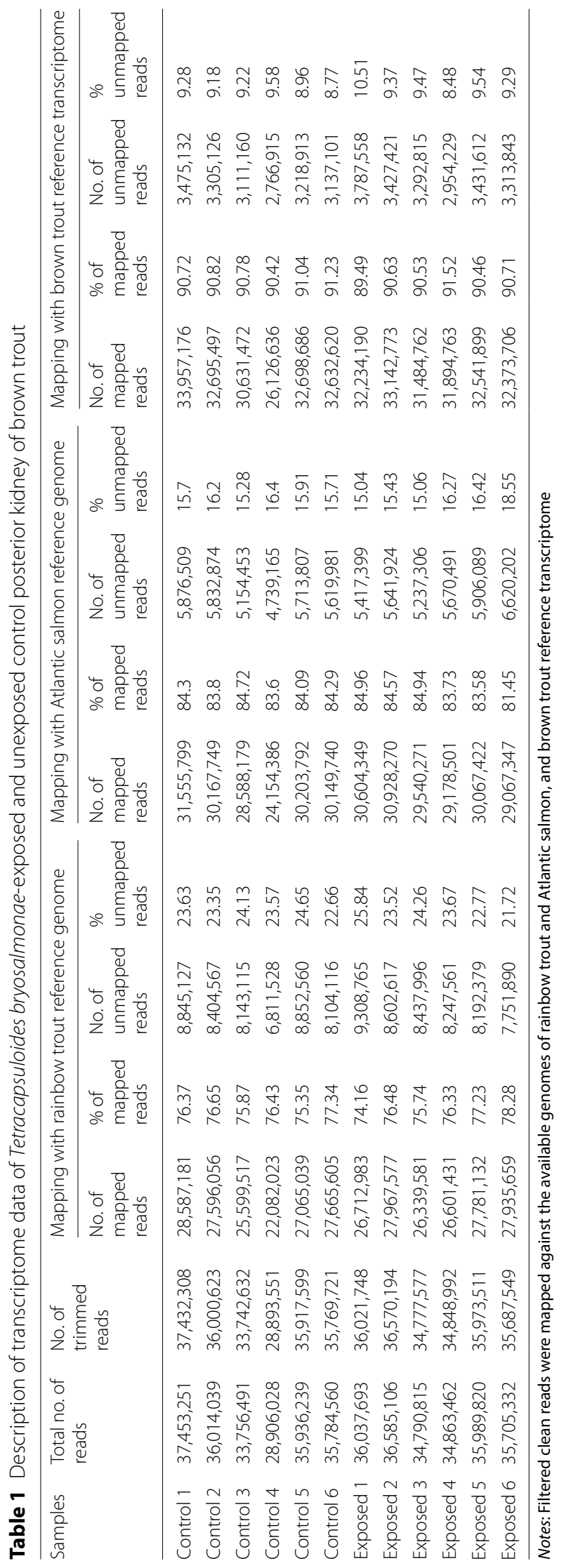


parasite-exposed kidney samples were compared with unexposed control kidney samples using the Empirical analysis of DGE tool which implements the Exact Test for two-group comparisons in the CLC Genomics Workbench [30]. A total count filter cut-off value of 5.0 was set to exclude features with low read counts across all samples. All features showing a false discovery rate, adjusted $P$-value $<0.01$ and fold change $\geq|2|$ were considered as differentially expressed. Moreover, global Pearson's correlation was analysed between samples for $\log _{2}$ $(\mathrm{TPM}+1)$ normalized RNA-seq values using ggcorrplot package [31]. The differentially expressed contigs including non-annotated transcripts were re-annotated using NCBI BLASTX and BLASTN tools with a cut-off threshold of E-value 1.0E-3 in the NCBI non-redudant database using Blast2GO [32].

\section{Gene ontology, enrichment and pathway analysis}

Differentially expressed genes (DEGs) were subjected to gene ontology (GO) and enrichment analysis for biological process, molecular function, and cellular components. This was performed in the ClueGO version 2.5.4 plugin [33] of the Cytoscape version 3.7.1 software platform [34]. Due to the non-availability of GO data for brown trout, the analysis was performed based on human GO data. Therefore, all the brown trout gene identifiers were converted to HUGO nomenclature and provided as input in ClueGO [35]. The analysis was done for up- and downregulated genes, separately. A minimum of three genes were used as the cut-off to find the GO term and two-sided hypergeometric statistical testing corrected with the Bonferoni step-down method $(P<0.05)$ and a kappa score of four was used as the cut-off. Furthermore, the DEGs were analyzed in Kyoto Encyclopedia of Genes and Genomes (KEGG) pathway database using online KEGG mapper tool under the reference pathway, KO [36].

\section{Validation of genes by quantitative real time PCR}

Twelve DEGs were selected to validate the expression profile of RNA-seq such as complement C1q like-2 (C1QL2), calcium-binding protein S100-A1 (S100A1), Mucin-7 (MUC7), C-X-C chemokine receptor type 1-like (CXCR1), C-C chemokine receptor type 5-like (CCR5), $\mathrm{H}-2$ class II histocompatibility antigen gamma chainlike (CD74), cathepsin-B (CTSB), apelin receptor A-like (APLNR), PEX5-related protein-like (PEX5L), matrix metallopeptidase 28 (MMP28), solute carrier family 16 member 4 (SLC16A4) and tomoregulin-1-like (TMEFF1). Gene-specific primers were designed according to sequence data of the kidney transcriptome using NCBI Primer-BLAST online tool. One $\mu \mathrm{g}$ of total RNA was used for the synthesize of cDNA using iScript cDNA Synthesis
Kit (Bio-Rad, Hercules, USA). The cDNA samples of exposed and unexposed control posterior kidneys $(n=6)$ were subjected to quantitative real time PCR (qRT-PCR) with two technical replicates using the optimized gene primers (Additional file 1). qRT-PCR was performed in a final volume of $20 \mu \mathrm{l}$, which contained $4 \mu \mathrm{l}$ of 1:10-fold diluted cDNA, $0.5 \mu \mathrm{M}$ of each primer, $1 \times$ SsoAdvanced $^{\mathrm{TM}}$ Universal SYBR Green Supermix (Bio-Rad) and DEPCtreated sterile distilled water. After 5 min of cDNA denaturation at $95{ }^{\circ} \mathrm{C}, 37$ cycles were performed at $95{ }^{\circ} \mathrm{C}$ for $30 \mathrm{~s}, 57{ }^{\circ} \mathrm{C}$ for $30 \mathrm{~s}$ and $72{ }^{\circ} \mathrm{C}$ for $30 \mathrm{~s}$ in a CFX96 Touch Real-Time PCR detection system (Bio-Rad, München, Germany). At the end of all gene expression cycling protocols, melting curve analysis was performed to validate amplification specificity under the following conditions: $57{ }^{\circ} \mathrm{C}$ for $30 \mathrm{~s}$ to $95{ }^{\circ} \mathrm{C}$ with an increment of $0.5{ }^{\circ} \mathrm{C}$ for $10 \mathrm{~s}$. Elongation factor alpha [28] was used as a reference gene to normalize the test samples. The $2^{-\Delta \Delta \mathrm{Ct}}$ method was calculated to determine the relative gene expression presented as the fold increase or decrease of the exposed group relative to the unexposed control group (mean expression level adjusted to 1). The statistical difference between groups was determined using the two-tailed unpaired Student's t-test with Welch's correction. Linear regression analysis was performed on corresponding $\log _{2}$ fold change values of RNA-seq and qRT-PCR to evaluate the relationship between them. For all statistical tests, $P$-value of $<0.05$ was regarded as significant and the data were analyzed in R statistical software version 3.5.1 [37].

\section{Results}

\section{Mapping of sequence reads and analysis of differentially expressed genes}

A total of 421.6 million clean single-end reads with a length of 100 bases were obtained by sequencing all 12 libraries. Approximately, 28.89 to 37.43 million singleend reads were obtained from each library (Table 1 ). The clean reads mapped to 74,449 out of 75,257 contigs $(98.2 \%)$ in the reference transcriptome and none of the reads mapped to 808 contigs in the reference transcriptome. Furthermore, global correlation analysis of expression levels between samples showed positive correlation between the biological replicates (Fig. 2). Comparison between exposed and unexposed control groups revealed 1169 DEGs (fold change $\geq|2|$, adjusted $P$-value $<0.01$ ), out of 75,257 contigs present on the reference brown trout transcriptome assembly. This accounts for $1.55 \%$ of the total contigs available in the reference brown trout transcriptome. DEGs were visualized in a heatmap and a volcano plot, which show that the number of upregulated DEGs were higher than the downregulated DEGs (Figs. 3, 4). Out of 1169 DEGs, 864 genes (74\%) were upregulated and 305 genes (26\%) were downregulated (Additional 


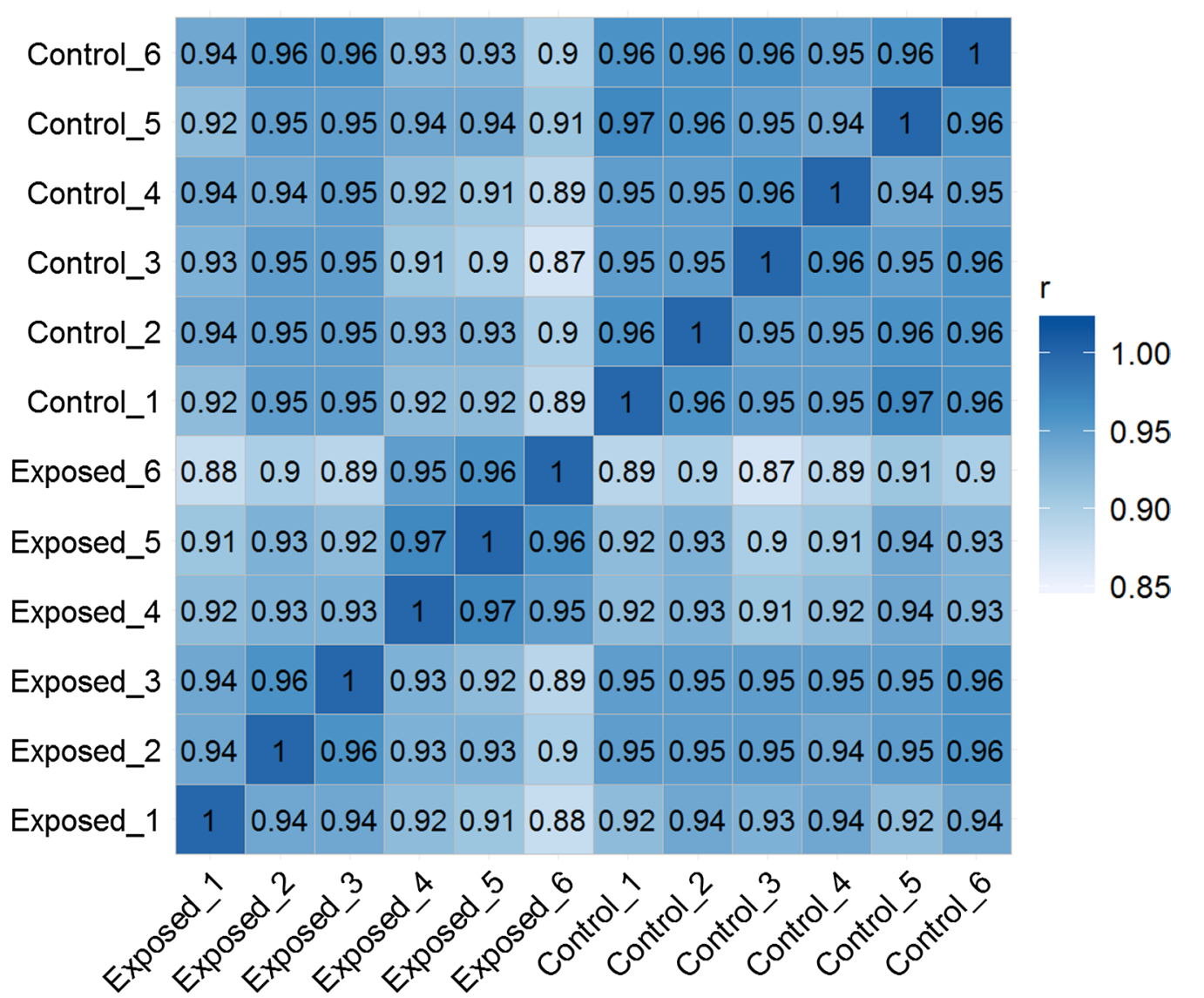

Fig. 2 Global correlation matrix of gene expression levels between samples. Heatmap showing Pearson's correlation coefficient $(r)$ for log 2 $(T P M+1)$ normalized RNA-seq values across samples, indicating positive correlation between biological replicates

file 2). DEGs related to immune system and disease process were identified using GO and KEGG pathway analysis.

\section{Functional annotation of differentially expressed up- and downregulated genes}

Out of 1169 DEGs, gene identifiers could be assigned for 1075 transcripts (91.95\%). Majority of them were associated with the biological processes such as regulation of immune system process (58.54\%), vesiclemediated transport (9.76\%), leucocyte activation (9.76\%), cellular response to unfolded proteins (5.69\%), and transport $(4.88 \%)$. GO terms related to immune system were most enriched among the upregulated genes. The upregulated genes were part of cellular components such as vesicle (63.16\%), side membrane (15.79\%), endomembrane system (13.16\%), cytosol (2.63\%), cytoplasmic parts (2.63\%), and actin cytoskeleton $(2.63 \%)$. The upregulated genes were involved in molecular functions such as cytokine receptor activity
(20\%), binding identical proteins (20\%), peptides (20\%), enzymes (20\%), and cytoskeleton proteins (20\%) (Additional files 3,4$)$.

The downregulated genes were associated with the biological processes such as endopeptidase regulatory activity (20\%), phosphatidylcholine biosynthetic process $(20 \%)$, connective tissue development (10\%), protein polymerization (10\%), hormone metabolic process $(10 \%)$, collagen catabolic process $(10 \%)$, monocarboxylic acid transport (10\%), and female pregnancy (10\%). Moreover, within cellular components category the downregulated genes were associated with melanosome $(38.46 \%)$, cluster of actin-based cell projections (15.38\%), cell-cell contact zone (7.69\%), sarcolemma (7.69\%), endosome lumen (7.69\%), sarcoplasm (7.69\%), spectrin-associated cytoskeleton (7.69\%), and lipid droplet (7.69\%). In addition, the downregulated genes have molecular functions such as endopeptidase regulator activity $(55.56 \%)$, proteoglycan $(22.22 \%)$, spectrin binding $(11.11 \%)$, and symporter activity $(11.11 \%)$ (Additional files 3, 5). 


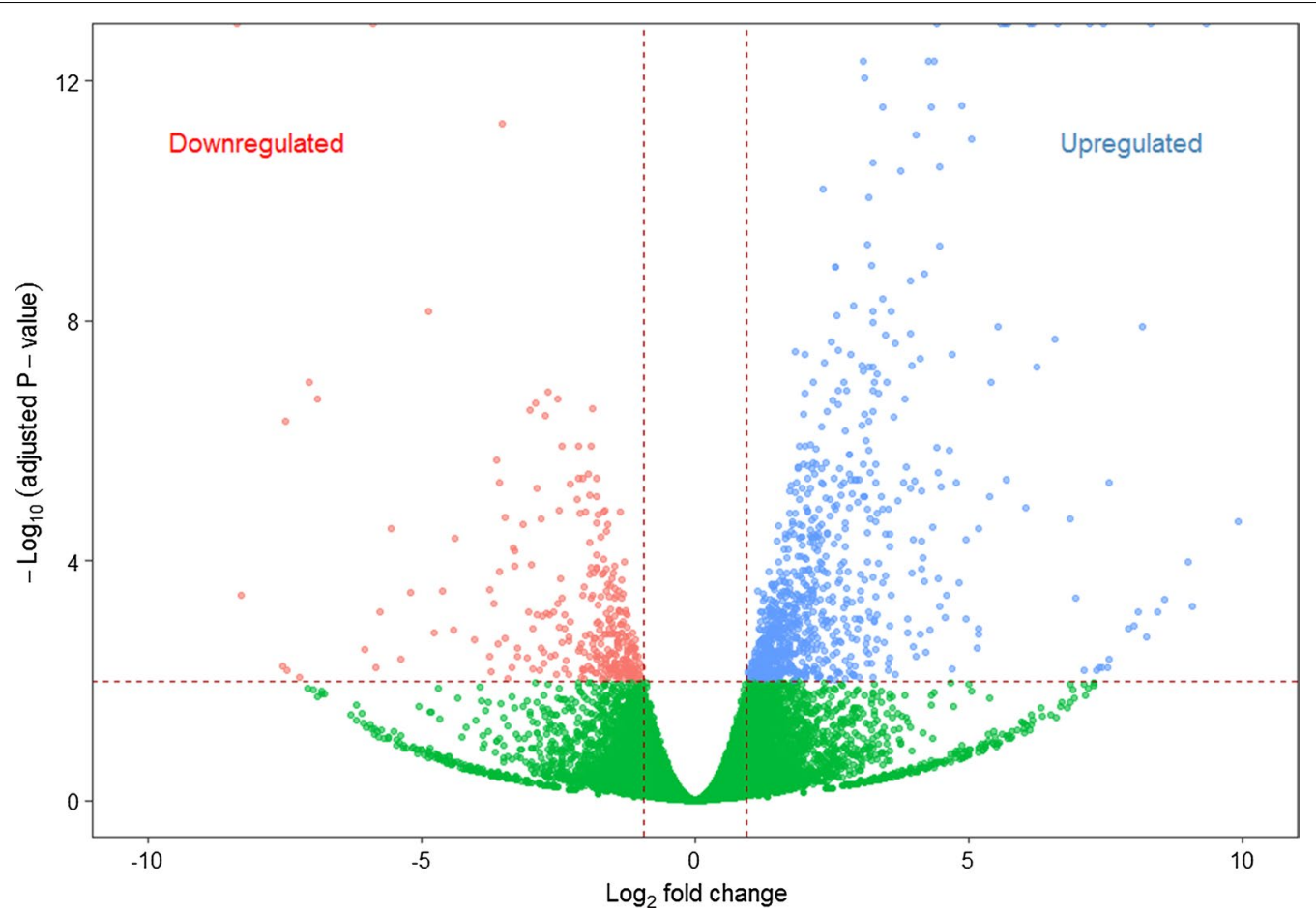

Fig. 3 Volcano plot of differently expressed genes of posterior kidney. $x$-axis represents $\log _{2}$ transformed fold change and the $y$-axis indicates - $\log _{10}$ transformed adjusted significance. Each dot indicates an individual gene that is significantly upregulated genes (blue), downregulated genes (red) and non-significantly regulated genes (green). The horizontal line represents adjusted $P$-value $<0.01$ cut-off and the vertical lines represent the absolute value of fold change greater than or equal to two

\section{KEGG pathway}

The KEGG pathway assigned 571 out of 1169 DEGs $(48.8 \%)$ to 282 pathways in the KEGG database (Additional file 6). Out of these 282 pathways, 21 were categorized under immune system pathways (Table 2). Among the immune-related pathways, the most DEGs were assigned to chemokine signaling pathway followed by NOD-like receptor signaling, natural killer cell mediated cytotoxicity, toll-like receptor signaling, and C-type lectin receptor signaling pathways. The list of immune genes assigned in representative immune related pathways are shown in Table 3. In addition to immune-related pathways the DEGs were also assigned to metabolic (35 genes), cytokine-cytokine receptor interaction (27 genes), JAK-STAT signaling (13 genes), endocytosis (11 genes), necroptosis (10 genes), and apoptosis (9 genes) pathways.

\section{Validation of transcriptional regulation}

All selected DEGs were differentially up or downregulated in the exposed samples, relative to the unexposed control samples in qRT-PCR, that is, C1QL2 $\left(t_{(5.01)}=-4.2, P=0.007\right)$, S100A1 $\left(t_{(5.04)}=2.58\right.$, $P=0.04)$, MUC7 $\left(t_{(5.0)}=-2.6, P=0.04\right)$, CXCR1 $\left(t_{(5.07)}=-3.06, P=0.02\right), \operatorname{CCR} 5\left(t_{(5.05)}=-2.67\right.$,
$P=0.04)$, CD74 $\left(t_{(6.7)}=-2.72, P=0.03\right), \mathrm{CTSB}$ $\left(t_{(9.8)}=8.01, P<0.0001\right), \operatorname{APLNR}\left(t_{(8.1)}=3.45, P=0.008\right)$, $\operatorname{PEX5L}\left(t_{(9.9)}=3.1, P=0.01\right), \operatorname{MMP} 28\left(t_{(5.76)}=3.17\right.$, $P=0.02)$, SLC16A4 $\left(t_{(9.9)}=5.65, P=0.02\right)$ and TMEFF1 $\left(t_{(6.4)}=3.26, P=0.0002\right)$. As shown in Fig. 5 , the relative gene expression levels of selected genes measured by qRT-PCR were consistent with the corresponding RNAseq transcriptome data. A significant positive correlation $\left(r_{(10)}=0.968, P<0.0001\right)$ between the $\log _{2}$ fold change values of RNA-seq and qRT-PCR affirms the reliability and reproducibility of the RNA-seq analysis (Fig. 6).

\section{Discussion}

Fishes are lower vertebrates and their defence systems against the invading pathogens are comparable with those in mammalian higher vertebrates [38]. However, there are a few differences in the immune system between fish and mammals. Fish do not have bone marrow and lymph nodes; instead, the kidney functions as a major lymphoid organ in teleost fish and serves as both primary and secondary lymphoid organ [39]. Tetracapsuloides bryosalmonae is an interesting parasite that can develop and persist chronically in the kidney of brown trout. The PKD-survived brown trout acts as a reservoir of $T$. bryosalmonae and shed the infectious parasite via 


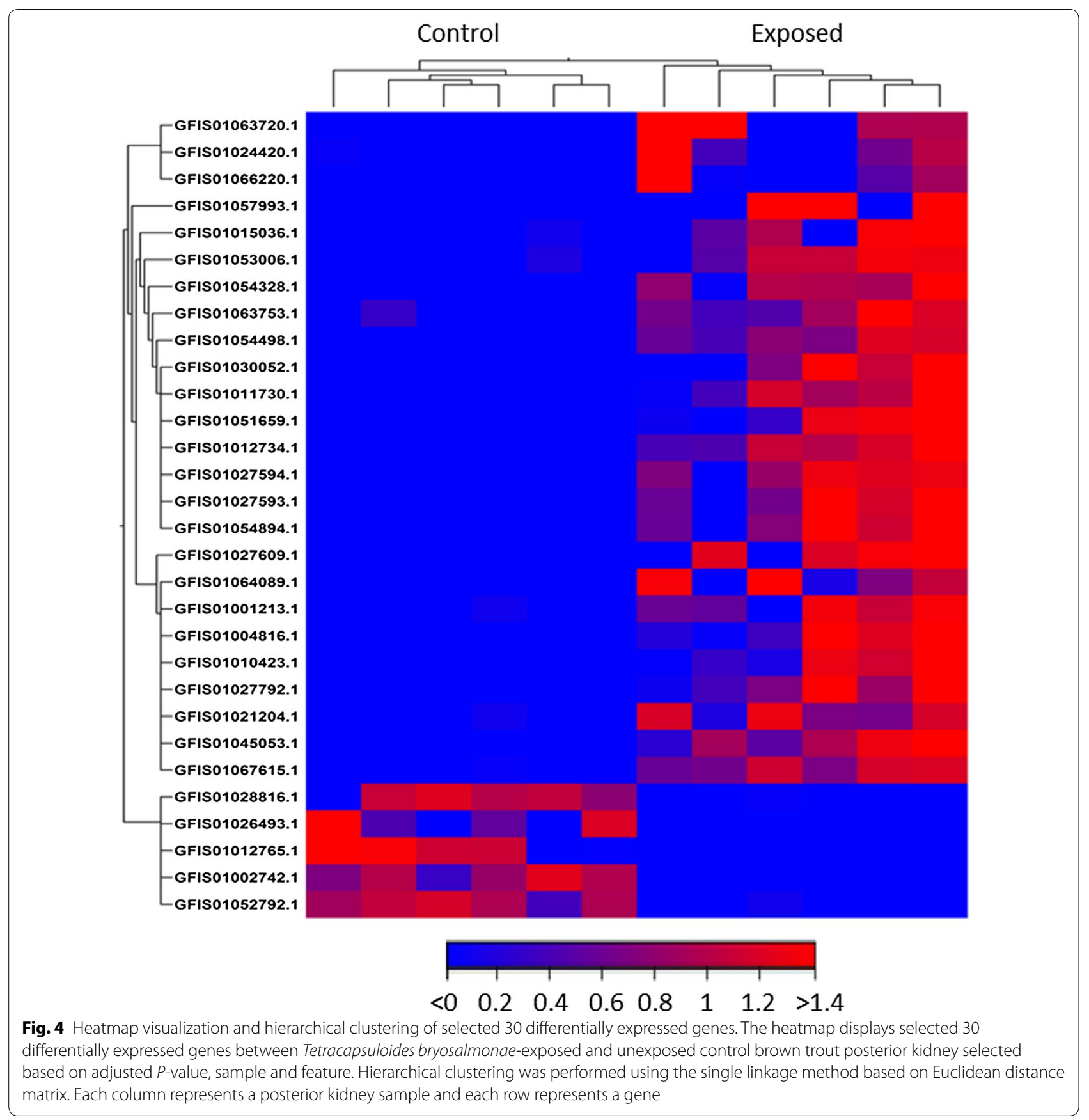

urine for its lifetime [18]. The host-parasite coevolution has come to a point where both brown trout and T. bryosalmonae can coexist together; however, the parasite has not coevolved with the dead-end rainbow trout host [17]. Previous studies based on PCR and qRT-PCR analyses have examined cellular responses and immune genes in the kidney of rainbow trout infected with $T$. bryosalmonae $[4,19-22,25,40]$ but only limited information is available about the brown trout $[24,26]$. The present study attempted to explore the global transcriptome of posterior kidney of brown trout to gain insights into the host molecular machineries during PKD.

Recent studies on transcriptome analysis in the posterior kidney of rainbow trout by Bailey et al. [23] at a late phase of infection (130 days post-infection) identified only 280 DEGs in the PKD affected group. Among the 280 DEGs, 36 were identified as immune-related genes and interestingly, 35 of them were downregulated, except 
Table 2 Distribution of the differentially expressed genes in immune related pathways categorized from the KEGG pathway database

\begin{tabular}{|c|c|c|c|}
\hline SI No & Pathway ID & Pathway & No. of genes \\
\hline 1 & ko04062 & Chemokine signaling & 12 \\
\hline 2 & ko04621 & NOD-like receptor signaling & 10 \\
\hline 3 & ko04650 & Natural killer cell mediated cytotoxicity & 9 \\
\hline 4 & ko04620 & Toll-like receptor signaling & 9 \\
\hline 5 & ko04625 & C-type lectin receptor signaling & 9 \\
\hline 6 & ko04659 & Th17 cell differentiation & 8 \\
\hline 7 & ko04640 & Hematopoietic cell lineage & 8 \\
\hline 8 & ko04662 & B cell receptor signaling & 7 \\
\hline 9 & ko04670 & Leukocyte transendothelial migration & 6 \\
\hline 10 & ko04658 & Th1 and Th2 cell differentiation & 6 \\
\hline 11 & ko04610 & Complement and coagulation cascades & 6 \\
\hline 12 & ko04672 & Intestinal immune network for IgA production & 5 \\
\hline 13 & ko04660 & T cell receptor signaling & 5 \\
\hline 14 & ko04666 & Fc gamma R-mediated phagocytosis & 5 \\
\hline 15 & ko04622 & RIG-I-like receptor signaling & 4 \\
\hline 16 & ko04657 & IL-17 signaling & 4 \\
\hline 17 & ko04611 & Platelet activation & 4 \\
\hline 18 & ko04612 & Antigen processing and presentation & 3 \\
\hline 19 & ko04623 & Cytosolic DNA-sensing & 3 \\
\hline 20 & ko04624 & Toll and Imd signaling & 2 \\
\hline 21 & ko04664 & Fc epsilon RI signaling & 2 \\
\hline
\end{tabular}

Notes: The pathway analysis mapped 571 out of 1169 DEGs (48.8\%) to 282 pathways, including 21 immune system pathways in the KEGG database

for single Ig IL-1-related receptor gene. At this late stage of parasite development, rainbow trout host exhibited a trade-off by reducing immune actions and increasing metabolic processes to recover from the disease [23]. In our study even after observing stringent selection criteria (adjusted $P<0.01$ ), we identified 1169 DEGs, of which 864 were upregulated and 305 genes were downregulated in the posterior kidney of brown trout. Furthermore, GO analysis revealed that most of the upregulated genes were associated with the regulation of immune system process. This high number of DEGs in the kidney of brown trout may be due to the active immune response against the parasite.

\section{Host immune response}

Our transcriptomic analysis identified an intense immune response in the posterior kidney of brown trout against $T$. bryosalmonae, characterized by the involvement of various elements of both innate and adaptive immune system. Previous investigations on PKD suggest proliferation of lymphocytes, reduction of the myeloid cell population, and complex interaction of Th1 and Th2 cells during pathogenesis in the affected rainbow trout [4, 20-22, 26]. In our study, cytokines and associated genes were clearly overrepresented among the upregulated DEGs including chemokines, interferons, interleukins, tumor necrosis factors, transforming growth factors and colony stimulating factors.

Chemokines are crucial elements of the innate immune system involved in chemo-attraction and trafficking of various immune cells to the site of infection and serve as a bridge between innate and adaptive defence system [41]. Neutrophil chemotactic factor CXCL8, had a peak expression at 50 days post-exposure in brown trout kidney in response to T. bryosalmonae [26]. In the present study, chemokines and their receptors (CXCL12, CXCL13-like, CXCR1-like, CXCR5-like, CCR5-like, CCL4, and CCL11-like) were predominantly upregulated in the posterior kidney of brown trout, except for CXCR3-like (- 2.4-fold) gene. In contrast, CCL4, CXCF1A and CCL13 were downregulated in the posterior kidney of rainbow trout during the late phase of PKD [23]. Previous studies suggest that chemokine molecules were activated in fish during parasitic infections such as Ichthyophthirius multifiliis [42] and Cryptocaryon irritans [43]. Similarly, CCL19 known for its chemotactic properties was upregulated in the head kidney of the turbot (Scophthalmus maximus) infected with the intestinal myxozoan parasite Enteromyxum scophthalmi [44]. $\mathrm{B}$ cells $\left(\mathrm{IgM}^{+}\right.$and $\left.\mathrm{IgT}^{+}\right)$isolated from the intestine of rainbow trout infected with Ceratomyxa shasta showed expression of chemokine receptor CCR7 [45]. 
Table 3 List of the differentially expressed genes mapped to representative immune-related pathways by KEGG pathway analysis

\begin{tabular}{|c|c|c|c|c|}
\hline SI no & Gene code & Description & Fold change & Regulation \\
\hline \multicolumn{5}{|c|}{ Chemokine signaling } \\
\hline 1 & ADCY9 & Adenylate cyclase type 9 & 3.59 & Up \\
\hline 2 & CCL11 & C-C motif chemokine 11/eotaxin & 9.56 & Up \\
\hline 3 & CCL4 & C-C motif chemokine 4 & 13.42 & Up \\
\hline 4 & CCR5 & C-C chemokine receptor type 5 -like & 4.31 & Up \\
\hline 5 & CXCL12 & Stromal cell-derived factor 1 precursor & 3.0 & Up \\
\hline 6 & CXCL13 & C-X-C motif chemokine 13-like & 4.99 & Up \\
\hline 7 & CXCR1 & C-X-C chemokine receptor type 1 -like & 4.47 & Up \\
\hline 8 & CXCR3 & C-X-C chemokine receptor type 3-like & -2.49 & Down \\
\hline 9 & CXCR5 & C-X-C chemokine receptor type 5-like & 2.64 & Up \\
\hline 10 & $\mathrm{FOXO3}$ & Forkhead box $\mathrm{O} 3$ & 4.36 & Up \\
\hline 11 & GNG13 & Guanine nucleotide-binding protein $\mathrm{G}(\mathrm{I}) / \mathrm{G}(\mathrm{S}) / \mathrm{G}(\mathrm{O})$ subunit gamma-13 & 3.53 & Up \\
\hline 12 & PXN & Paxillin-like & 3.11 & Up \\
\hline \multicolumn{5}{|c|}{ NOD-like receptor signaling } \\
\hline 1 & ATG16L1 & Autophagy related 16-like 1 & 2.88 & Up \\
\hline 2 & ATG5 & Autophagy related 5 homolog & 4.89 & Up \\
\hline 3 & CASR & Extracellular calcium-sensing receptor-like protein & 3.26 & Up \\
\hline 4 & CTSB & Cathepsin B & -3.01 & Down \\
\hline 5 & IFNAR1 & Interferon alpha/beta receptor 1a-like & 2.34 & Up \\
\hline 6 & IFNAR2 & Interferon alpha/beta receptor 2 & 2.72 & Up \\
\hline 7 & $J U N$ & Transcription factor AP-1-like & 3.75 & Up \\
\hline 8 & NLRP3 & NACHT, LRR and PYD domains-containing protein 3 & -2.37 & Down \\
\hline 9 & PYCARD & Apoptosis-associated speck-like protein containing a CARD & 2.53 & Up \\
\hline 10 & RIPK3 & Receptor-interacting serine/threonine-protein kinase 3 & 2.70 & Up \\
\hline \multicolumn{5}{|c|}{ Natural killer cell mediated cytotoxicity } \\
\hline 1 & $\mathrm{BID}$ & BH3-interacting domain death agonist-like & 2.77 & Up \\
\hline 2 & ICAM1 & Intercellular adhesion molecule 1-like isoform X2 & -7.45 & Down \\
\hline 3 & IFNAR1 & Interferon alpha/beta receptor 1a-like & 2.34 & Up \\
\hline 4 & IFNAR2 & Interferon alpha/beta receptor 2 & 2.72 & Up \\
\hline 5 & IFNGR1 & Interferon gamma receptor 1a & 2.33 & Up \\
\hline 6 & $\mathrm{IGH}$ & Immunoglobulin heavy chain & 147.29 & Up \\
\hline 7 & ITGB2 & Integrin beta-2-like & 3.0 & Up \\
\hline 8 & PRF1 & Perforin-1-like & -3.18 & Down \\
\hline 9 & PTPN11 & Tyrosine-protein phosphatase non-receptor type 11 & 2.81 & Up \\
\hline \multicolumn{5}{|c|}{ Th17 cell differentiation } \\
\hline 1 & CD3E & CD3epsilon & 5.68 & Up \\
\hline 2 & IFNGR1 & Interferon gamma receptor 1a & 2.33 & Up \\
\hline 3 & IL21R & Interleukin-21 receptor-like & 2.69 & Up \\
\hline 4 & IL6ST & Interleukin-6 receptor subunit beta-like & 3.28 & Up \\
\hline 5 & IRF4 & Interferon regulatory factor 4 & 7.28 & Up \\
\hline 6 & $J U N$ & Transcription factor AP-1-like & 3.75 & Up \\
\hline 7 & NFKBIE & Nuclear factor of kappa light polypeptide gene enhancer in B-cells inhibitor, epsilon & 9.05 & Up \\
\hline 8 & TGFBR1 & TGF-beta receptor type-1 & -2.14 & Down \\
\hline \multicolumn{5}{|c|}{ Hematopoietic cell lineage } \\
\hline 1 & CD2 & T-cell surface antigen CD2 & 2.89 & Up \\
\hline 2 & CD22 & B-cell receptor CD22-like & 3.10 & Up \\
\hline 3 & CD34 & Hematopoietic progenitor cell antigen CD34-like & -3.13 & Down \\
\hline 4 & CD3E & CD3epsilon & 5.68 & Up \\
\hline 5 & CR2 & Complement receptor type 2-like & 3.25 & Up \\
\hline
\end{tabular}


Table 3 (continued)

\begin{tabular}{|c|c|c|c|c|}
\hline SI no & Gene code & Description & Fold change & Regulation \\
\hline 6 & $\mathrm{IGH}$ & Immunoglobulin heavy chain & 147.29 & Up \\
\hline 7 & MME & Neprilysin-like & -4.06 & Down \\
\hline 8 & TFRC & Transferrin receptor protein 1-like & 4.97 & Up \\
\hline \multicolumn{5}{|c|}{ B cell receptor signaling } \\
\hline 1 & BLNK & B-cell linker protein-like isoform X1 & 3.43 & Up \\
\hline 2 & CD22 & B-cell receptor CD22-like & 3.10 & Up \\
\hline 3 & CD79A & B-cell antigen receptor complex-associated protein alpha chain-like & 2.76 & Up \\
\hline 4 & CR2 & Complement receptor type 2-like & 3.25 & Up \\
\hline 5 & IGH & Immunoglobulin heavy chain & 147.29 & Up \\
\hline 6 & JUN & Transcription factor AP-1-like & 3.75 & Up \\
\hline 7 & NFKBIE & Nuclear factor of kappa light polypeptide gene enhancer in B-cells inhibitor, epsilon & 9.05 & Up \\
\hline \multicolumn{5}{|c|}{ Th1 and Th2 cell differentiation } \\
\hline 1 & CD3E & CD3 epsilon & 5.68 & Up \\
\hline 2 & IFNGR1 & Interferon gamma receptor $1 a$ & 2.33 & Up \\
\hline 3 & IL $12 B$ & Interleukin-12 subunit beta-like & 2.31 & Up \\
\hline 4 & IL12RB2 & Interleukin-12 receptor subunit beta-2-like & 3.50 & Up \\
\hline 5 & JUN & Transcription factor AP-1-like & 3.75 & Up \\
\hline 6 & NFKBIE & Nuclear factor of kappa light polypeptide gene enhancer in B-cells inhibitor, epsilon & 9.05 & Up \\
\hline \multicolumn{5}{|c|}{ Complement and coagulation cascades } \\
\hline 1 & $\mathrm{~A} 2 \mathrm{M}$ & Alpha-2-macroglobulin-like & -7.82 & Down \\
\hline 2 & C8G & Complement C8 gamma chain & -5.78 & Down \\
\hline 3 & CR2 & Complement receptor type 2-like & 3.25 & Up \\
\hline 4 & F2RL2 & Proteinase-activated receptor 3-like (coagulation factor II (thrombin) receptor) & 5.81 & Up \\
\hline 5 & ITGB2 & Integrin beta-2-like & 3.0 & Up \\
\hline 6 & PLAUR & Urokinase plasminogen activator surface receptor-like & -3.17 & Down \\
\hline
\end{tabular}

Notes: Chemokine signaling pathway has the predominant share of differentially expressed genes among the immune related pathways. Interestingly, most of the immune genes were upregulated in the T. bryosalmonae-exposed posterior kidney of brown trout

Interferons (IFNs) are cytokines responsible for mobilizing the host defence system against the invading pathogens. IFN- $\alpha / \beta$ receptor subunits (IFNAR1-like and IFNAR2-like) and interferon- $\gamma$ receptor subunit (IFNGR1) were upregulated in the posterior kidney of brown trout during T. bryosalmonae proliferation. Type I IFNs (IFN- $\alpha$ and IFN- $\beta$ ) binds to IFNAR1/ IFNAR2 receptors, whereas Type II IFN (IFN- $\gamma$ ) binds to IFNGR1/IFNGR2 receptors, but both signal their respective Janus-activated kinases (JAK) molecules initiating a cascade of immune action against invading pathogens [46]. SOCS proteins can negatively regulate IFN pathway and associated inflammatory response in fish. SOCS-1 has been demonstrated as a potential suppressor of IFN pathway and associated JAKSTAT signaling pathway in Atlantic salmon [47]. In our study, we observed upregulation of SOCS-1-like gene (3.6-fold) in the posterior kidney of T. bryosalmonaeexposed brown trout, which may have a negative effect on IFN production during PKD. Higher expression of SOCS-1 and SOCS-3 may play an important role in immunosuppression in rainbow trout, which facilitates host evasion process of T. bryosalmonae [20, 25, 48].

Interleukin (IL12B-like) and interleukin receptors (IL12RB2-like, IL13RA2-like, IL21R-like and IL6ST-like) were upregulated in the posterior kidney of brown trout during T. bryosalmonae proliferation. However, interleukin molecules (IL2RB2, IL21R, IL6RA, IL12B, IL4/13A, IL-1RA and IL-1RII) were downregulated during late phase of PKD infection in rainbow trout [23]. IL12 indirectly promotes antiparasitic activity of macrophages and cytolytic function of natural killer cells [49]. Furthermore, IL-13 produced by Th2 cells is known for its defensive response against metazoan parasites [50]. This indicates that interleukins may play an active role in the brown trout against T. bryosalmonae development. However, in the present study downregulation of proinflammatory cytokine IL16-like (-2.7-fold) was noticed in the posterior kidney. IL16 is known for its function in the modulation of T-cell response and chemoattraction of immune cells [49]. Furthermore, transforming growth factor beta induced protein (4.7-fold) was upregulated and tumour 


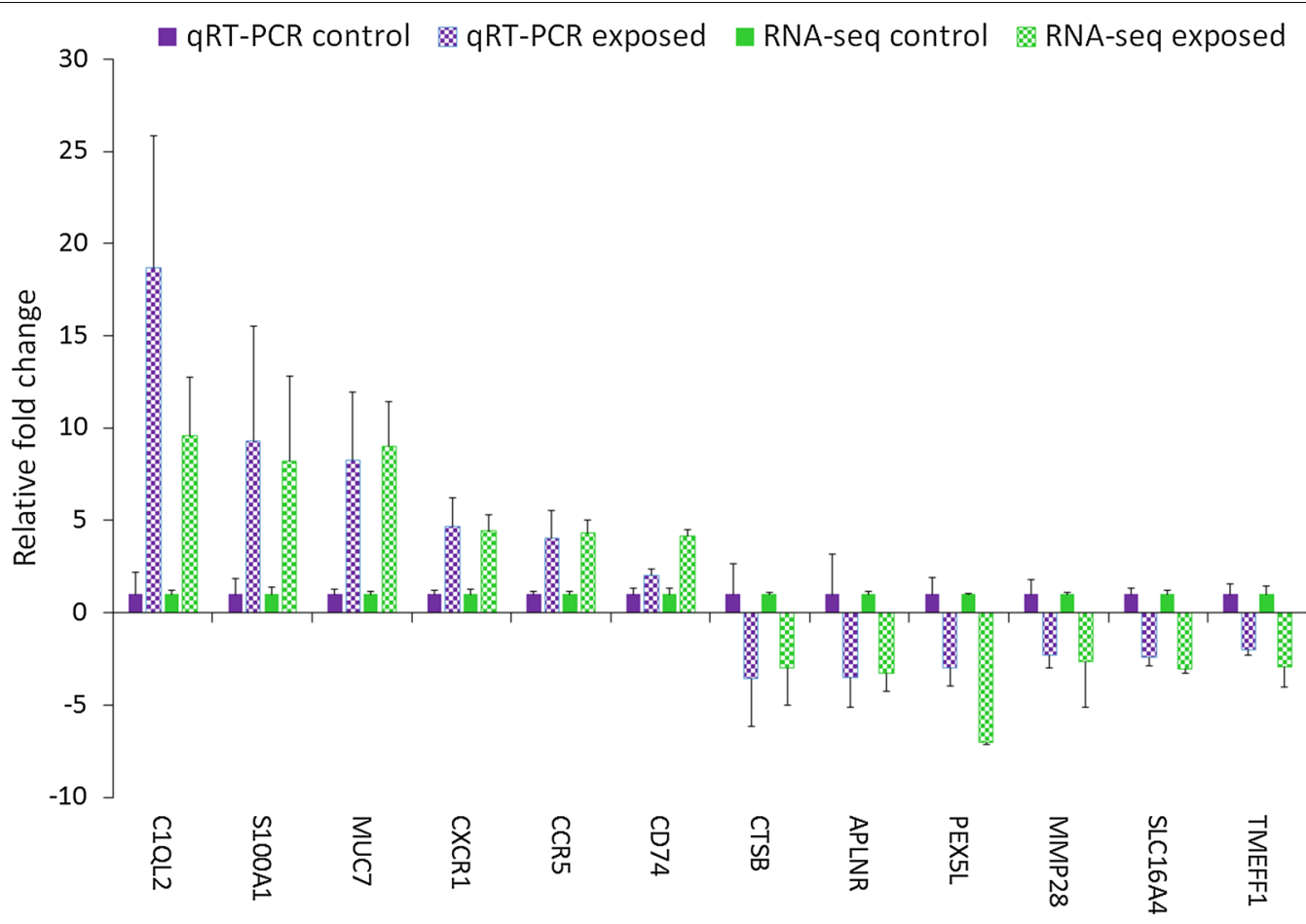

Fig. 5 Validation of RNA-seq analysis by qRT-PCR on selected genes. The gene expression values are represented as relative fold change (mean \pm SEM) of Tetracapsuloides bryosalmonae-exposed group compared to the unexposed control group $(n=6)$. The relative gene expression represented as the fold increase or decrease of the exposed group compared to the unexposed control group were calculated using $2^{-\Delta \Delta C t}$ method and the mean expression levels were adjusted to one

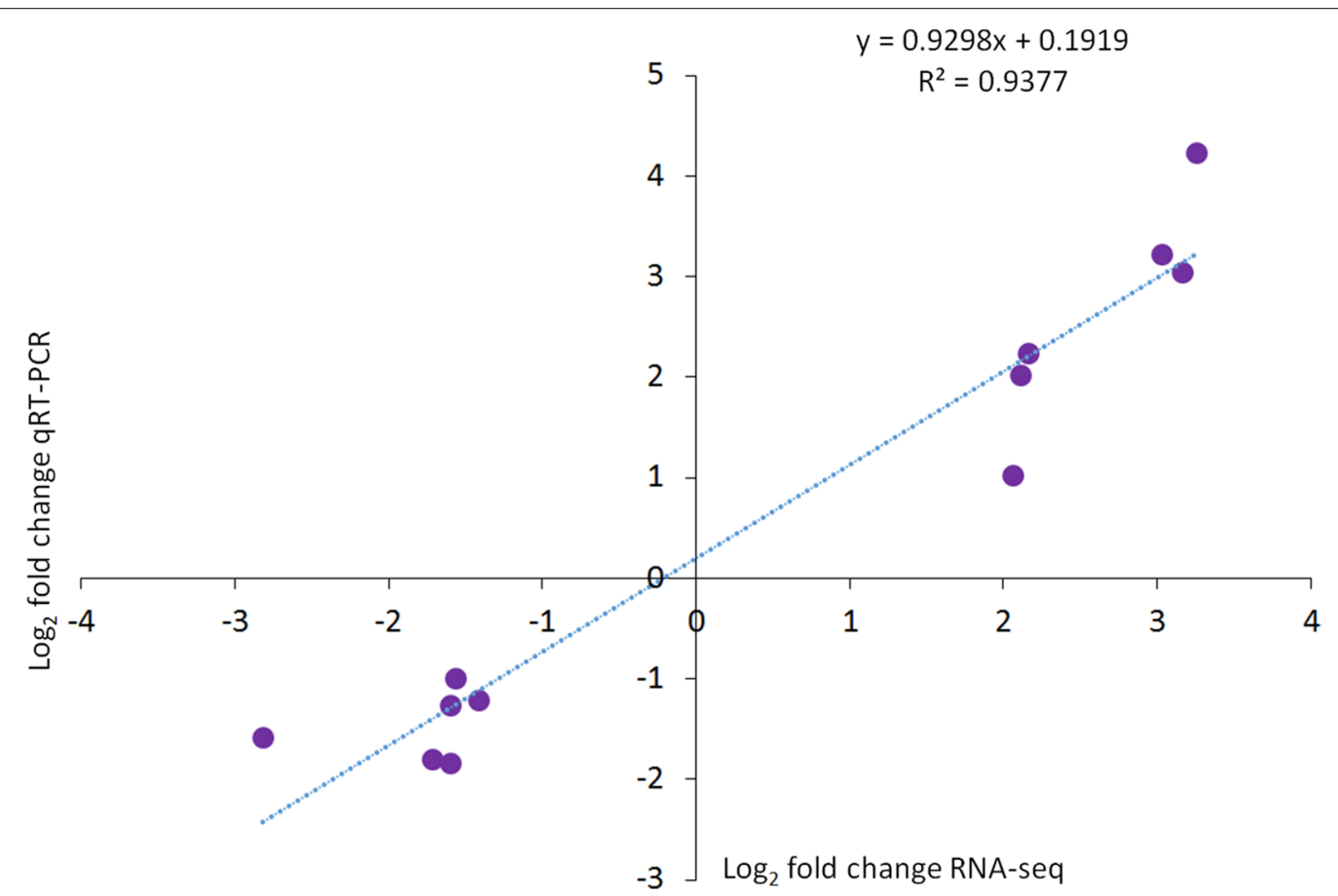

Fig. 6 Linear regression plot between RNA-seq and qRT-PCR. The $\log _{2}$ fold change values for the RNA-seq and qRT-PCR are plotted along with the linear fit line showing a significant Pearson's correlation coefficient $r_{(10)}=0.968, P<0.0001$ and a coefficient of determination $R^{2}=0.937$ 
necrosis factor alpha induced protein 8 ( -2.2 -fold) was downregulated in the kidney of brown trout in response to T. bryosalmonae.

IL12, IL16, IL21 and TNF $\alpha$ are pro-inflammatory markers whereas IL13 and TGF $\beta$ are markers of antiinflammatory function. Interestingly, IL6 has both proinflammatory and anti-inflammatory functions [51]. Gorgoglione et al. [20] observed higher expression of anti-inflammatory genes (IL6, IL10, IL11, nIL-IF, SOCS1 and SOCS3) in T. bryosalmonae-infected rainbow trout. Additionally, these authors did not find any correlation between the expression of pro-inflammatory molecules (TNF $\alpha$, IL1 $\beta$ and COX2 isoforms) and T. bryosalmonae prevalence. Similarly, Bailey et al. [26] also found unresponsiveness of pro-inflammatory cytokines (TNF $\alpha$, IL1 $\beta$ and IFN $\gamma$ ) in PKD infected brown trout [26]. Taken together, PKD pathogenesis tends the inflammatory mechanism towards anti-inflammatory phenotype in trout [52].

$\mathrm{T}$ cells have a crucial role in the immune defence against the invading pathogens and act as an effector by directly killing the infected cell or coordinating other immune cells against the invading pathogen [53]. T cells are characterized based on the surface T-cell receptors such as $\alpha \beta$-T cells and $\gamma \delta$-T cells. We identified a strong positive regulation and proliferation of $\alpha \beta-T$ cells in the posterior kidney of brown trout during T. bryosalmonae development. $\alpha \beta-T$ cells can recognize parasite-derived antigens presented by major histocompatibility complex (MHC) and a noticeable upregulation of MHC class I alpha chain (3075.7-fold) and MHC class II DP beta 2 (2.4-fold) were observed in the posterior kidney of brown trout in our study. Similar upregulation of MHC class I molecule was observed in the spleen of rainbow trout during Yersinia ruckeri infection [54]. However, experimental infection with the intestinal myxozoan parasite $E$. scophthalmi in turbot resulted in downregulation of the MHC class I molecule, which was attributed to the host immune evasion by the parasite [55]. Signatures of both Th1 (T-bet, IFN $\gamma$, TNF $\alpha$ and IL-2) and Th2 (GATA3, IL4/13A, IL10 and FOXP3) cells were differentially regulated during $T$. bryosalmonae infection in rainbow trout and brown trout $[20,26,40]$. Interestingly, we also found upregulation of marker of regulatory T cell [CD3E] (5.6fold) in brown trout exposed to T. bryosalmonae. This suggests that PKD pathogenesis drive towards a dysregulated Th cell activity in salmonids [20, 26] possibly associated with the chronic infection nature of this disease [56].

Complement system is a major effector system of innate and acquired immunity which aids in the pathogen clearance mechanism [57]. In mammals, the complement system has been studied extensively; however, this is least studied in teleost fish. Complement associated molecules like C4A (15.4-fold), C1QL2 (9.5-fold) and CR2-like (3.2fold) were upregulated whereas C8G (- 5.7-fold) was downregulated in the posterior kidney of brown trout in response to T. bryosalmonae. The role of complement system against parasitic infection in fish has been documented. In salmonids, activation of the alternative pathway of the complement system was shown to act against the monogenean parasites, Gyrodactylus salaries [58] and Discocotyle sagittata [59]. Similarly, parasitic ciliate I. multifiliis infection led to the higher expression of $\mathrm{C} 3$ in the skin mucus and lymphoid organs of rainbow trout [60], and the proteins involved in pathogen recognition and complement activation [61]. C8 is a part of membrane attack complex and the downregulation of C8G in the present study may be attributed to the parasiteinduced modulation to escape host immune response. Tetracapsuloides bryosalmonae proliferation in the kidney of brown trout has generated a complex interaction of immune responses and further detailed studies are essential to understand their specific roles during hostparasite interaction.

\section{Calcium-binding proteins}

In humans and other higher vertebrates, regulation of intracellular calcium is associated with homeostasis and is regulated by calcium-binding proteins. These proteins have clinical importance in inflammation, cancer, neurology, allergy, cardiomyopathy and immune response [62]. Nevertheless, calcium-binding proteins and their importance on homeostasis are least studied in fish. In the present study, two calcium-binding proteins S100A1 (8.1-fold) and calretinin CALB2 (14.8-fold) were upregulated in the posterior kidney of brown trout in response to T. bryosalmonae. Calretinin is a vitamin D-dependent calcium-binding protein known to interact with cytoskeletal components [63], whereas S100 is involved in the modulation of specific signal transduction pathway, control of cell growth and its proliferation [64]. In contrast to our results, omics studies have revealed downregulation of S100 in the kidney of the gilthead sea bream (Sparus aurata) infected with the myxozoan parasite Enteromyxum leei [65]. Protein interaction experiments have identified active interaction between calcium-binding protein S100A9 in the kidney of brown trout and T. bryosalmonae [66]. This explains the importance of these calcium-binding proteins in the kidney of brown trout during PKD pathogenesis and further experiments are required to explore their specific roles.

\section{Apoptosis}

Parasites have been identified to modulate the host apoptotic regulatory system to facilitate their invasion, differentiation, and replication in their host. 
Intracellular parasites can inhibit apoptosis in the cells where they dwell, whereas, extracellular parasites are known to induce apoptosis in the host immune cells that hinder their evasion or the cells that have components of their diet [67]. Host genes involved in the regulation of apoptosis were differentially expressed in our study. Pronounced upregulation of CASP14-like (1704.4-fold), BCL2L11 (4.0-fold), BCL7B (2.2-fold), and BIRC2 (2.3-fold) were observed in brown trout during T. bryosalmonae proliferation. However, BIRC2 is known for its role in the inhibition of apoptosis. Similarly, in previous studies CASP14 precursor protein was identified in the kidney of PKD-affected brown trout kidney by antibody-based protein purification followed by ESI-MS [66]. It is important to highlight that the inducers of apoptosis, cathepsin molecules CTSB ( -3.0 -fold), CTSD (-3.6-fold), and CTSK ( -6.5 -fold) were downregulated in the posterior kidney of parasiteexposed brown trout. Cathepsins are multifunctional proteolytic enzymes involved in various immune processes including antimicrobial activity [68]. Our results suggest that $T$. bryosalmonae proliferation strongly influence apoptotic process in brown trout. Similar differential expression of host apoptosis molecules was also observed in the kidney transcriptome of rainbow trout during PKD recovery phase [23].

\section{Endopeptidase regulatory activity}

Molecules involved in endopeptidase regulatory activity had a clear downregulation pattern in the posterior kidney of parasite-exposed brown trout. Genes involved in the negative regulation of endopeptidase regulatory activity (A2M-like, AMBP-like, GAPDH and SERPINH1) were downregulated in brown trout exposed with $T$. bryosalmonae. A2M is a protease inhibitor known to inhibit the proteases produced by parasites during host infection process. A2M is reported to have defense role against the fish parasites such Cryptobia salmositica in salmonids [69], and Trypanoplasma borreli and I. multifiliis in common carp [70]. In higher vertebrates, apart from anti-protease activity A2M is known for its role in the activation and proliferation of macrophages [71], involvement in the inhibition of clotting cascade [72], and mediate T-cell proliferation [73]. Moreover, A2M can bind with hormones, cytokines, endopeptidases, histones, mitogens, and various ions [74]. In our transcriptome results, A2Mlike gene was downregulated $(-7.8$-fold) in the posterior kidney of brown trout exposed to T. bryosalmonae. This suggests that $T$. bryosalmonae may have evolved to modulate and reduce the activities of A2M protease inhibitors in the kidney of brown trout to facilitate parasite proliferation and release into the aquatic environment via urine.

\section{Collagen catabolic process}

Genes associated with collagen catabolic process (CTSB, CTSD, CTSK-like, MMP13, MMP28-like and VSIR) were downregulated in the the posterior kidney of brown trout in response to T. bryosalmonae. MMP13 and MMP28 represent matrix metalloproteinases family of genes and have a major role in host extracellular matrix degradation and remodeling. MMP13 has been suggested to play a crucial role in inflammatory response of Atlantic salmon during salmon louse (Lepeophtheirus salmonis) parasitic infection. Activation of MMP9 and MMP13, and the downregulation of extracellular structural protein, prolonged the wound healing process at the site of salmon louse attachment [75]. Bailey et al. [23] reported upregulation of collagen catabolic genes such MMP16 and CTSB in the kidney of rainbow trout during late phase of PKD infection. The upregulation of host collagen catabolic protease genes might influence the sporogenesis of $T$. bryosalmonae in rainbow trout dead-end host. However, we could not find any statistically significant $(\geq|2.0|$ fold and adjusted $P$-value $<0.01$ ) upregulation of collagen catabolic genes in the kidney of brown trout during active phase of T. bryosalmonae proliferation. Taken together, the downregulation of collagen catabolic proteases in brown trout might be a possible trade-off between host and parasite, by reducing the host collagen catabolic proteases activity against the parasite and accelerating the tissue repair process in the kidney. This may facilitate brown trout and T. bryosalmonae to coexist together. We reported previously that the kidney of brown trout was found recovered after five years of T. bryosalmonae exposure that could excrete viable parasite spores infectious to bryozoans [18]. Further investigations are required to check whether any protease inhibitors of $T$. bryosalmonae are upregulated during developmental stages in the kidney of brown trout.

\section{Connective tissue development}

Among the genes related to connective tissue development, special attention must be paid to connective tissue growth factor $\mathrm{CCN} 2$ of $\mathrm{CCN}$ gene family, which enhances cell proliferation, myofibroblast differentiation, and extracellular matrix production. In higher vertebrates dysregulation of CCN2 may result in the inhibition of tissue repair process, which leads to excessive scarring and fibrosis [76]. Trypanosoma cruzi infection in humans interfered with host fibrogenic response and resulted in the downregulation of CCN2 in foreskin fibroblast cells [77]. Similarly, in the present study, we identified a downregulation of CCN2-like (-3.2-fold) gene in the kidney and correlated with the tissue damage in the kidney during parasite development. 


\section{Host-parasite coexistence}

From the present study and previous works, it is evident that both rainbow trout and brown trout exhibits a strong immune action against $T$. bryosalmonae during the active infection phase [20-22]. However, downregulation of immune response was noticed at the late recovery phase of T. bryosalmonae infection in rainbow trout [23]. In spite of a strong defence response from both of its hosts, T. bryosalmonae could accomplish sporogenesis in brown trout, but not in rainbow trout [17]. Furthermore, Kumar et al. [24] described differences in the pattern of expression between brown trout and rainbow trout during active $T$. bryosalmonae infection, particularly in host genes involved in cell proliferation, cell growth, endocytic pathway, anti-inflammatory and humoral immune responses. Tetracapsuloides bryosalmonae has evolved to employ certain unknown mechanism to survive the immune response of brown trout. In addition, the downregulation of host proteases observed in the present study may be due to protease inhibitors produced by $T$. bryosalmonae. It would be interesting to study the aspects of parasite counter-mechanism against the brown trout immune response and the role of parasite protease inhibitors, in T. bryosalmonae sporogenesis in brown trout. Further study is needed to explore T. bryosalmonae transcriptome during active development in brown trout, which can provide detailed insights about the molecular strategies adopted by the parasite to facilitate its coexistence with brown trout host.

\section{Conclusions}

To our knowledge, this is the first transcriptome profiling of the posterior kidney of brown trout during the active phase of $T$. bryosalmonae proliferation. Functional annotation of differentially expressed genes showed that the upregulated genes were associated with molecular functions such as cytokine receptor activity, binding identical proteins, peptides, enzymes, and cytoskeleton proteins. Whereas, the downregulated genes were associated with endopeptidase regulator activity, proteoglycan and spectrin binding, and symporter activity. The downregulation of host collagen catabolic proteases might be a possible trade-off between brown trout and T. bryosalmonae. Our study provides new insights into the brown trout-T. bryosalmonae interaction, particularly on the host immune components that acted against the parasite, and on the host genes modulated by the parasite to establish themselves in the host. However, further studies are needed to characterize the evasion strategy adopted by the parasite to reach the target organ kidney in the salmonid host.

\section{Supplementary information}

Supplementary information accompanies this paper at https://doi. org/10.1186/s13071-019-3823-y.

Additional file 1: Table S1. List of quantitative qRT-PCR primers used in this study.

Additional file 2: Table S2. List of all significant differentially expressed up- and downregulated genes.

Additional file 3: Table S3. Gene ontology terms enriched by up- and downregulated genes separately.

Additional file 4: Figure S1. Overview of biological processes of upregulated genes. Figure S2. Specific functional GO terms of biological processes of upregulated genes. Figure S3. Overview of cellular components of upregulated genes. Figure S4. Specific functional GO terms of cellular components of upregulated genes. Figure S5. Overview of molecular functions of upregulated genes. Figure S6. Specific functional GO terms of molecular functions of upregulated genes.

Additional file 5: Figure S7. Overview of biological processes of downregulated genes. Figure S8. Specific functional GO terms of biological processes of downregulated genes. Figure S9. Overview of cellular components of downregulated genes. Figure S10. Specific functional GO terms of cellular components of downregulated genes. Figure S11. Overview of molecular functions of downregulated genes. Figure S12. Specific functional GO terms of molecular functions of downregulated genes.

Additional file 6: Table S4. List of all pathways mapped in KEGG pathway analysis.

\section{Abbreviations}

APLNR: apelin receptor A-like; C1QL2: complement C1q like-2; CCR5: C-C chemokine receptor type 5-like; $\mathrm{CD} 74$ : $\mathrm{H}$-2 class II histocompatibility antigen gamma chain-like; CTSB: cathepsin-B; CXCR1: C-X-C chemokine receptor type 1-like; DEGs: differentially expressed genes; GO: gene ontology; H\&E: hematoxylin and eosin; IFNs: interferons; IHC: immunohistochemistry; JAK: Janus-activated kinases; KEGG: Kyoto Encyclopedia of Genes and Genomes; MHC: major histocompatibility complex; MMP28: matrix metallopeptidase 28; MUC7: mucin-7; PEX5L: PEX5-related protein-like; PKD: proliferative kidney disease; qRT-PCR: quantitative real time PCR; RNA-seq: RNA sequencing; SLC16A4 solute carrier family 16 member 4; SOCS: suppressors of cytokine signaling; SPF: specific pathogen free; TMEFF1: tomoregulin-1-like; TNFa: tumour necrosis factor alpha; wpe: weeks post-exposure.

\section{Acknowledgements}

The first author acknowledges the Indian Council of Agricultural Research, New Delhi, India for providing a PhD scholarship under Netaji Subhas - ICAR International Fellowship 2016-2017. We are thankful to the Next Generation Sequencing core facility, Vienna BioCenter, Austria for providing sequencing facility.

\section{Authors' contributions}

GK and MEM designed and supervised this study. AS performed the experiment. RE, AS and GK analyzed RNA-seq data and performed bioinformatics. AS drafted the manuscript. GK, RE and MEM reviewed the manuscript. All authors read and approved the final manuscript.

\section{Funding}

This work was funded by the Austrian Science Fund (FWF) Project No. P 30981B32 to GK.

\section{Availability of data and materials}

All raw sequence data have been submitted to the NCBI Short Read Archive (SRA) portal under NCBI Bioproject ID PRJNA542491.

\section{Ethics approval and consent to participate}

This study was approved by the institutional ethics committee of the University of Veterinary Medicine Vienna and the national authority, according to $\$ 26$ of the Austrian Law for Animal Experiments, Tierversuchsgesetz 2012 under 
approval number BMWFW-68.205/0181-WF/N/3b/2017. All experiments were performed in accordance with relevant guidelines and regulations.

\section{Consent for publication}

Not applicable.

\section{Competing interests}

The authors declare that they have no competing interests.

\section{Author details}

${ }^{1}$ Clinical Division of Fish Medicine, University of Veterinary Medicine, Vienna, Austria. ${ }^{2}$ VetCore Facility for Research, University of Veterinary Medicine, Vienna, Austria. ${ }^{3}$ Central Institute of Fisheries Education, Rohtak Centre, Rohtak, Haryana, India.

Received: 26 July 2019 Accepted: 21 November 2019 Published online: 29 November 2019

\section{References}

1. Henderson M, Okamura B. The phylogeography of salmonid proliferative kidney disease in Europe and North America. Proc R Soc B Biol Sci. 2004;271:1729-36.

2. Bettge K, Wahli T, Segner H, Schmidt-Posthaus H. Proliferative kidney disease in rainbow trout: time- and temperature-related renal pathology and parasite distribution. Dis Aquat Organ. 2009;83:67-76.

3. Bettge K, Segner H, Burki R, Schmidt-Posthaus H, Wahli T. Proliferative kidney disease (PKD) of rainbow trout: temperature- and time-related changes of Tetracapsuloides bryosalmonae DNA in the kidney. Parasitology. 2009;136:615-25.

4. Bailey C, Segner H, Casanova-Nakayama A, Wahli T. Who needs the hotspot? The effect of temperature on the fish host immune response to Tetracapsuloides bryosalmonae the causative agent of proliferative kidney disease. Fish Shellfish Immunol. 2017;63:424-37.

5. Wahli T, Knuesel R, Bernet D, Segner H, Pugovkin D, Burkhardt-Holm P, et al. Proliferative kidney disease in Switzerland: current state of knowledge. J Fish Dis. 2002;25:491-500.

6. Gorgoglione B, Kotob MH, Unfer G, El-Matbouli M. First proliferative kidney disease outbreak in Austria, linking to the aetiology of black trout syndrome threatening autochthonous trout populations. Dis Aquat Organ. 2016;119:117-28.

7. Montana fish, wildlife and parks. Montana State Government, USA. http:// fwp.mt.gov/news/newsReleases/headlines/nr_4278.html. Accessed 5 June 2019.

8. Morris DJ, Adams A. Transmission of Tetracapsuloides bryosalmonae (Myxozoa: Malacosporea), the causative organism of salmonid proliferative kidney disease, to the freshwater bryozoan Fredericella sultana. Parasitology. 2006;133:701-9.

9. Grabner DS, El-Matbouli M. Transmission of Tetracapsuloides bryosalmonae (Myxozoa: Malacosporea) to Fredericella sultana (Bryozoa: Phylactolaemata) by various fish species. Dis Aquat Organ. 2008;79:133-9.

10. Morris DJ, Adams A. Sporogony of Tetracapsuloides bryosalmonae in the brown trout Salmo trutta and the role of the tertiary cell during the vertebrate phase of myxozoan life cycles. Parasitology. 2008;135:1075-92.

11. Grabner DS, El-Matbouli M. Tetracapsuloides bryosalmonae (Myxozoa: Malacosporea) portal of entry into the fish host. Dis Aquat Organ. 2010;90:197-206.

12. Clifton-Hadley R, Feist S. Proliferative kidney disease in brown trout Salmo trutta further evidence of a myxosporean aetiology. Dis Aquat Organ. 1989;6:99-103.

13. Chilmonczyk S, Monge D, De Kinkelin P. Proliferative kidney disease: cellular aspects of the rainbow trout, Oncorhynchus mykiss (Walbaum), response to parasitic infection. J Fish Dis. 2002;25:217-26.

14. Schmidt-Posthaus H, Bettge K, Forster U, Segner H, Wahli T. Kidney pathology and parasite intensity in rainbow trout Oncorhynchus mykiss surviving proliferative kidney disease: time course and influence of temperature. Dis Aquat Organ. 2012;97:207-18.

15. Zapata A, Diez B, Cejalvo T, Frías CG, Cortés A. Ontogeny of the immune system of fish. Fish Shellfish Immunol. 2006;20:126-36.
16. Zwollo P, Cole S, Bromage E, Kaattari S. B cell heterogeneity in the teleost kidney: evidence for a maturation gradient from anterior to posterior kidney. J Immunol. 2014;174:6608-16.

17. Kumar G, Abd-Elfattah A, Saleh M, El-Matbouli M. Fate of Tetracapsuloides bryosalmonae (Myxozoa) after infection of brown trout Salmo trutta and rainbow trout Oncorhynchus mykiss. Dis Aquat Organ. 2013;107:9-18.

18. Soliman H, Kumar G, El-Matbouli M. Tetracapsuloides bryosalmonae persists in brown trout Salmo trutta for five years post exposure. Dis Aquat Organ. 2018;127:151-6.

19. Holland JW, Gould CRW, Jones CS, Noble LR, Secombes CJ. The expression of immune-regulatory genes in rainbow trout, Oncorhynchus mykiss, during a natural outbreak of proliferative kidney disease (PKD). Parasitology. 2003;126:595-102.

20. Gorgoglione B, Wang T, Secombes CJ, Holland JW. Immune gene expression profiling of proliferative kidney disease in rainbow trout Oncorhynchus mykiss reveals a dominance of anti-inflammatory, antibody and Th cell-like activities. Vet Res. 2013;44:55.

21. Bailey C, Segner H, Wahli T. What goes around comes around: an investigation of resistance to proliferative kidney disease in rainbow trout Oncorhynchus mykiss (Walbaum) following experimental re-exposure. J Fish Dis. 2017;40:1599-612.

22. Abos B, Estensoro I, Perdiguero P, Faber M, Hu Y, Rosales PD, et al. Dysregulation of $B$ cell activity during proliferative kidney disease in rainbow trout. Front Immunol. 2018;9:1203.

23. Bailey C, von Siebenthal EW, Rehberger K, Segner H. Transcriptomic analysis of the impacts of ethinylestradiol (EE2) and its consequences for proliferative kidney disease outcome in rainbow trout (Oncorhynchus mykiss). Comp Biochem Physiol Part C Toxicol Pharmacol. 2019;222:31-48.

24. Kumar G, Abd-Elfattah A, El-Matbouli M. Identification of differentially expressed genes of brown trout (Salmo trutta) and rainbow trout (Oncorhynchus mykiss) in response to Tetracapsuloides bryosalmonae (Myxozoa). Parasitol Res. 2015;1 14:929-39.

25. Kotob MH, Kumar G, Saleh M, Gorgoglione B, Abdelzaher M. Differential modulation of host immune genes in the kidney and cranium of the rainbow trout (Oncorhynchus mykiss) in response to Tetracapsuloides bryosalmonae and Myxobolus cerebralis co-infections. Parasites Vectors. 2018;11:326.

26. Bailey C, Strepparava N, Wahli T, Segner H. Exploring the immune response, tolerance and resistance in proliferative kidney disease of salmonids. Dev Comp Immunol. 2019;90:165-75.

27. Sudhagar A, Kumar G, El-Matbouli M. Transcriptome analysis based on RNA-seq in understanding pathogenic mechanisms of diseases and the immune system of fish: a comprehensive review. Int J Mol Sci. 2018;19:245.

28. Kumar G, Abd-Elfattah A, El-Matbouli M. Differential modulation of host genes in the kidney of brown trout Salmo trutta during sporogenesis of Tetracapsuloides bryosalmonae (Myxozoa). Vet Res. 2014;45:101.

29. Pasquier J, Cabau C, Nguyen T, Jouanno E, Severac D, Braasch I, et al. Gene evolution and gene expression after whole genome duplication in fish: the PhyloFish database. BMC Genomics. 2016;17:368.

30. Robinson MD, Smyth GK. Small-sample estimation of negative binomial dispersion, with applications to SAGE data. Biostatistics. 2008;9:321-32.

31. Kassambara A. ggcorrplot: visualization of a correlation matrix using "ggplot2". CRAN; 2019. https://cran.r-project.org/web/packages/ggcor rplot/ggcorrplot.pdf. Accessed 16 Sept 2019.

32. Conesa A, Götz S, García-Gómez JM, Terol J, Talón M, Robles M. Blast2GO: a universal tool for annotation, visualization and analysis in functional genomics research. Bioinformatics. 2005;21:3674-6.

33. Bindea G, Mlecnik B, Hackl H, Charoentong P, Tosolini M, Kirilovsky A, et al. ClueGO: a Cytoscape plug-in to decipher functionally grouped gene ontology and pathway annotation networks. Bioinformatics. 2009;25:1091-3.

34. Shannon P, Markiel A, Ozier O, Baliga NS, Wang JT, Ramage D, et al. Cytoscape: a software environment for integrated models of biomolecular interaction networks. Genome Res. 2003;13:2498-504.

35. Pacitti D, Lawan MM, Feldmann J, Sweetman J, Wang T, Martin SAM, et al. Impact of selenium supplementation on fish antiviral responses: a whole transcriptomic analysis in rainbow trout (Oncorhynchus mykiss) fed supranutritional levels of Sel-Plex ${ }^{\circledR}$. BMC Genomics. 2016;17:116. 
36. Kanehisa M, Goto S, Sato Y, Furumichi M, Tanabe M. KEGG for integration and interpretation of large-scale molecular data sets. Nucleic Acids Res. 2012:40:109-14

37. R Core Team. R: A language and environment for statistical computing. Vienna, Austria; 2018. https://www.r-project.org/. Accessed 25 May 2019.

38. Riera Romo M, Pérez-Martínez D, Castillo Ferrer C. Innate immunity in vertebrates: an overview. Immunology. 2016;148:125-39.

39. Press $C M L$, Evensen $\varnothing$. The morphology of the immune system in teleost fishes. Fish Shellfish Immunol. 1999;9:309-18.

40. Wang T, Holland JW, Martin SAM, Secombes CJ. Sequence and expression analysis of two Thelper master transcription factors, T-bet and GATA3, in rainbow trout Oncorhynchus mykiss and analysis of their expression during bacterial and parasitic infection. Fish Shellfish Immunol. 2010;29:705-15.

41. Sokol CL, Luster AD. The chemokine system in innate immunity. Cold Spring Harb Perspect Biol. 2015;7:a016303.

42. Syahputra K, Kania PW, Al-Jubury A, Jafaar RM, Dirks RP, Buchmann K. Transcriptomic analysis of immunity in rainbow trout (Oncorhynchus mykiss) gills infected by Ichthyophthirius multifilis. Fish Shellfish Immunol. 2019;86:486-96

43. Hu Y, Li A, XuY, Jiang B, Lu G, Luo X. Transcriptomic variation of locallyinfected skin of Epinephelus coioides reveals the mucosal immune mechanism against Cryptocaryon irritans. Fish Shellfish Immunol. 2017;66:398-410.

44. Ronza P, Robledo D, Bermúdez R, Losada AP, Pardo BG, Sitjà-Bobadilla A, et al. RNA-seq analysis of early enteromyxosis in turbot (Scophthalmus maximus): new insights into parasite invasion and immune evasion strategies. Int J Parasitol. 2016;46:507-17.

45. Ordás MC, Castro R, Dixon B, Sunyer JO, Bjork S, Bartholomew J, et al. Identification of a novel CCR7 gene in rainbow trout with differential expression in the context of mucosal or systemic infection. Dev Comp Immunol. 2012;38:302-11

46. Negishi $\mathrm{H}$, Taniguchi T, Yanai $\mathrm{H}$. The interferon (IFN) class of cytokines and the IFN regulatory factor (IRF) transcription factor family. Cold Spring Harb Perspect Biol. 2018;10:a028423.

47. Skjesol A, Liebe T, Iliev DB, Thomassen EIS, Tollersrud LG, Sobhkhez M, et al. Functional conservation of suppressors of cytokine signaling proteins between teleosts and mammals: Atlantic salmon SOCS1 binds to JAK STAT family members and suppresses type I and II IFN signaling. Dev Comp Immunol. 2014:45:177-89.

48. Wang T, Gorgoglione B, Maehr T, Holland JW, Vecino JLG, Wadsworth S, et al. Fish suppressors of cytokine signaling (SOCS): gene discovery, modulation of expression and function. J Signal Transduct. 2011;2011:905813.

49. Akdis M, Aab A, Altunbulakli C, Azkur K, Costa RA, Crameri R, et al. Interleukins (from IL-1 to IL-38), interferons, transforming growth factor $\beta$, and TNF-a: receptors, functions, and roles in diseases. J Allergy Clin Immunol. 2016;138:984-1010.

50. Allen JE, Maizels RM. Diversity and dialogue in immunity to helminths. Nat Rev Immunol. 2011;11:375

51. Turner MD, Nedjai B, Hurst T, Pennington DJ. Cytokines and chemokines: at the crossroads of cell signalling and inflammatory disease. Biochim Biophys Acta. 2014;1843:2563-82.

52. Sitjà-Bobadilla A, Schmidt-Posthaus H, Wahli T, Holland JW, Secombes CJ. Fish immune responses to myxozoa. In: Okamura B, Gruhl A, Bartholomew $J L$, editors. Myxozoan evolution, ecology and development. Cham: Springer International Publishing; 2015. p. 253-80.

53. Wan F, Hu C, Ma J, Gao K, Xiang L, Shao J. Characterization of $\gamma \delta$ T cells from zebrafish provides insights into their important role in adaptive humoral immunity. Front Immunol. 2017;7:675.

54. Kumar G, Hummel K, Noebauer K, Welch TJ, Razzazi-Fazeli E, El-Matbouli M Proteome analysis reveals a role of rainbow trout lymphoid organs during Yersinia ruckeri infection process. Sci Rep. 2018;8:13998.

55. Robledo D, Ronza P, Harrison PW, Losada A, Bermúdez R, Pardo BG, et al. RNA-seq analysis reveals significant transcriptome changes in turbot (Scophthalmus maximus) suffering severe enteromyxosis. BMC Genomics. 2014:15:1149.

56. Taylor MD, van der Werf N, Maizels RM. T cells in helminth infection: the regulators and the regulated. Trends Immunol. 2012;33:181-9.

57. Boshra H, Li J, Sunyer JO. Recent advances on the complement system of teleost fish. Fish Shellfish Immunol. 2006;20:239-62.

58. Harris PD, Soleng A, Bakke TA. Killing of Gyrodactylus salaris (Platyhelminthes, Monogenea) mediated by host complement. Parasitology. 1998:117:137-43.
59. Rubio-Godoy M, Porter R, Tinsley RC. Evidence of complement-mediated killing of Discocotyle sagittata (Platyhelminthes, Monogenea) oncomiracidia. Fish Shellfish Immunol. 2004;17:95-103.

60. Sigh J, Lindenstrøm T, Buchmann K. The parasitic ciliate Ichthyophthirius multifilis induces expression of immune relevant genes in rainbow trout, Oncorhynchus mykiss (Walbaum). J Fish Dis. 2004;27:409-17.

61. Saleh M, Kumar G, Abdel-Baki AS, Dkhil MA, El-Matbouli M, Al-Quraishy S. Quantitative proteomic profiling of immune responses to /chthyophthirius multifiliis in common carp skin mucus. Fish Shellfish Immunol. 2019;84:834-42

62. Heizmann CW. Ca ${ }^{2+}$-binding proteins of the EF-hand superfamily: diagnostic and prognostic biomarkers and novel therapeutic targets. In: Heizmann CW, editor. Calcium-binding proteins EF-hand superfamily from basics to medical applications. New York: Springer; 2019. p. 157-86.

63. Marilley D, Schwaller B. Association between the calcium-binding protein calretinin and cytoskeletal components in the human colon adenocarcinoma cell line WiDr. Exp Cell Res. 2000;259:12-22.

64. Donato R. Intracellular and extracellular roles of S100 proteins. Microsc Res Tech. 2003;60:540-51.

65. Davey GC, Calduch-Giner JA, Houeix B, Talbot A, Sitjà-Bobadilla A, Prunet $P$, et al. Molecular profiling of the gilthead sea bream (Sparus aurata L.) response to chronic exposure to the myxosporean parasite Enteromyxum leei. Mol Immunol. 2011;48:2102-12.

66. Kumar G, Gotesman M, El-Matbouli M. Interaction of Tetracapsuloides bryosalmonae, the causative agent of proliferative kidney disease, with host proteins in the kidney of Salmo trutta. Parasitol Res. 2015;114:1721-7.

67. James ER, Green DR. Manipulation of apoptosis in the host-parasite interaction. Trends Parasitol. 2004;20:280-7.

68. Cho JH, Park IY, Kim HS, Lee WT, Kim MS, Kim SC. Cathepsin D produces antimicrobial peptide parasin I from histone H2A in the skin mucosa of fish. FASEB J. 2002;16:429-31.

69. Zuo X, Woo P. Natural anti-proteases in rainbow trout, Oncorhynchus mykiss and brook charr, Salvelinus fontinalis and the in vitro neutralization of fish 2-macroglobulin by the metalloprotease from the pathogenic haemoflagellate, Cryptobia salmositica. Parasitology. 1997;114:375-81.

70. Onara DF, Forlenza M, Gonzalez SF, Rakus KL, Pilarczyk A, Irnazarow I, et al. Differential transcription of multiple forms of alpha-2-macroglobulin in carp (Cyprinus carpio) infected with parasites. Dev Comp Immunol. 2008;32:339-47.

71. Bonacci GR, Cáceres LC, Sánchez MC, Chiabrando GA. Activated a2-macroglobulin induces cell proliferation and mitogen-activated protein kinase activation by LRP-1 in the J774 macrophage-derived cell line. Arch Biochem Biophys. 2007;460:100-6.

72. Drew KL, Rice ME, Kuhn TB, Smith MA. Neuroprotective adaptations in hibernation: therapeutic implications for ischemia-reperfusion, traumatic brain injury and neurodegenerative diseases. Free Radic Biol Med. 2001;31:563-73.

73. Banks RE, Evans SW, Van Leuven F, Alexander D, McMahon MJ, Whicher JT. Measurement of the 'fast' or complexed form of a 2 macroglobulin in biological fluids using a sandwich enzyme immunoassay. J Immunol Methods. 1990;126:13-20.

74. Liu Q, Ling TY, Shieh HS, Johnson FE, Huang JS, Huang SS. Identification of the high affinity binding site in transforming growth factor- $\beta$ involved in complex formation with $\mathrm{a}_{2}$-macroglobulin. Implications regarding the molecular mechanisms of complex formation between $\mathrm{a}_{2}$ macroglobulin and growth factors, cytokines, and hormones. J Biol Chem. 2001;276:46212-8.

75. Skugor S, Glover KA, Nilsen F, Krasnov A. Local and systemic gene expression responses of Atlantic salmon (Salmo salar L.) to infection with the salmon louse (Lepeophtheirus salmonis). BMC Genomics. 2008;9:498.

76. Shi-Wen X, Leask A, Abraham D. Regulation and function of connective tissue growth factor/CCN2 in tissue repair, scarring and fibrosis. Cytokine Growth Factor Rev. 2008;19:133-44.

77. Mott GA, Costales JA, Burleigh BA. A soluble factor from Trypanosoma cruz inhibits transforming growth factor-ß-induced MAP kinase activation and gene expression in dermal fibroblasts. PLoS ONE. 2011;6:e23482.

\section{Publisher's Note}

Springer Nature remains neutral with regard to jurisdictional claims in published maps and institutional affiliations. 